\title{
Behavior of thiosemicarbazones derived from some terpenones under acetylation conditions. Part II
}

\author{
Pablo D. Rouge ${ }^{a}$, Beatriz N. Brousse ${ }^{b}$, Albertina G. Moglioni ${ }^{b}$, Guillermo A. Cozzi ${ }^{\text {c, d }}$, \\ Angel Alvarez-Larena ${ }^{c}$, Norma $D^{\prime}$ Accorso $^{e}$, and Graciela Y. Moltrasio ${ }^{b}$ * \\ ${ }^{a}$ Centro de Química y Petroquímica (CEQUIPE) Instituto Nacional de Tecnología Industrial \\ (INTI) San Martín, Pcia. de Buenos Aires, Argentina \\ ${ }^{b}$ Departamento de Química Orgánica, Facultad de Farmacia y Bioquímica-Universidad de \\ Buenos Aires, Junín 956-1113 Buenos Aires-Argentina \\ c Servicio de Difracción de Rayos X, Universidad Autónoma de Barcelona, 08193 Bellaterra \\ España \\ ${ }^{d}$ Permanent address: Servicio Geológico Minero Argentino (SEGEMAR), Buenos Aires, \\ Argentina ${ }^{e}$ Departamento de Química Orgánica, Facultad de Ciencias Exactas y Naturales- \\ Universidad de Buenos Aires-Argentina \\ E-mail: gmoltra@ffyb.uba.ar
}

\section{Dedicated to Professor Rosa Lederkremer on her $70^{\text {th }}$ anniversary}

\begin{abstract}
Preparation of chiral heterocyclic compounds of the thiadiazoline types, starting from natural $\alpha, \beta$-unsaturated and bicyclic terpenones is described. Stereochemical assignment of the compounds synthesized was performed by NMR spectroscopy and X-ray analysis.
\end{abstract}

Keywords: Thiosemicarbazones, thiadiazolines, terpenoids, spiro-nitrogenheterocycles, spirosulphur heterocycles

\section{Intorduction}

Thiodiazoles and their derivatives make up a group of compounds that possess a wide spectrum of biological actions. ${ }^{1}$

Among the few general routes to obtain 1,3,4-thiadiazolines (TDZ), one of the most employed is that of heterocyclization of thiosemicarbazones (TSC) prepared from aldehydes and ketones (Scheme 1) under acylation conditions (acetic anhydride and pyridine) ${ }^{2}$ 


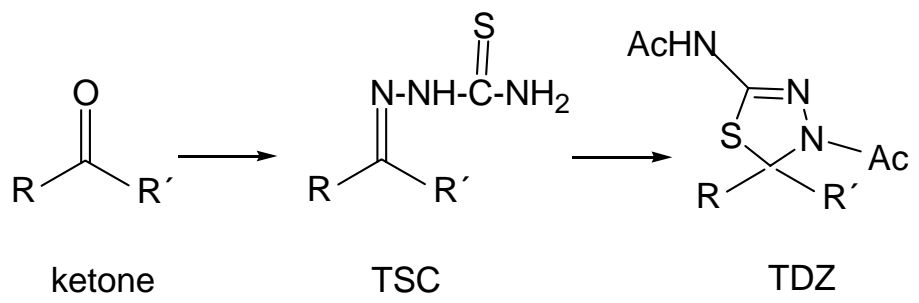

Scheme 1. 1,3,4-Thiadiazolines (TDZ) synthesis from ketones.

Resorting to this synthetic methodology, we have described the synthesis of several TSC and TDZ, derived from such aromatic ketones as diarylketones, indanones and tetralone. ${ }^{3}$ Many of these ketones are prochiral and, as it is obvious given the working conditions, the corresponding TDZ were formed as a racemic mixture.

Pursuing our investigation in the area, diverse homochiral TDZ were synthesized, applying the methodology of heterocyclization of TSC under acylation conditions. Likewise, TSC were derived from natural terpenones (mentone, fenchone and camphor). ${ }^{4}$ Configuration assignment of the new chiral center (C-2 of the heterocycle) was carried out by NMR experiments (2DNOESY) and in the special case of fenchone by X-ray crystallography.

Two possible mechanisms ${ }^{5}$ have been proposed for the this heterocyclization reaction, as shown in Scheme 2.
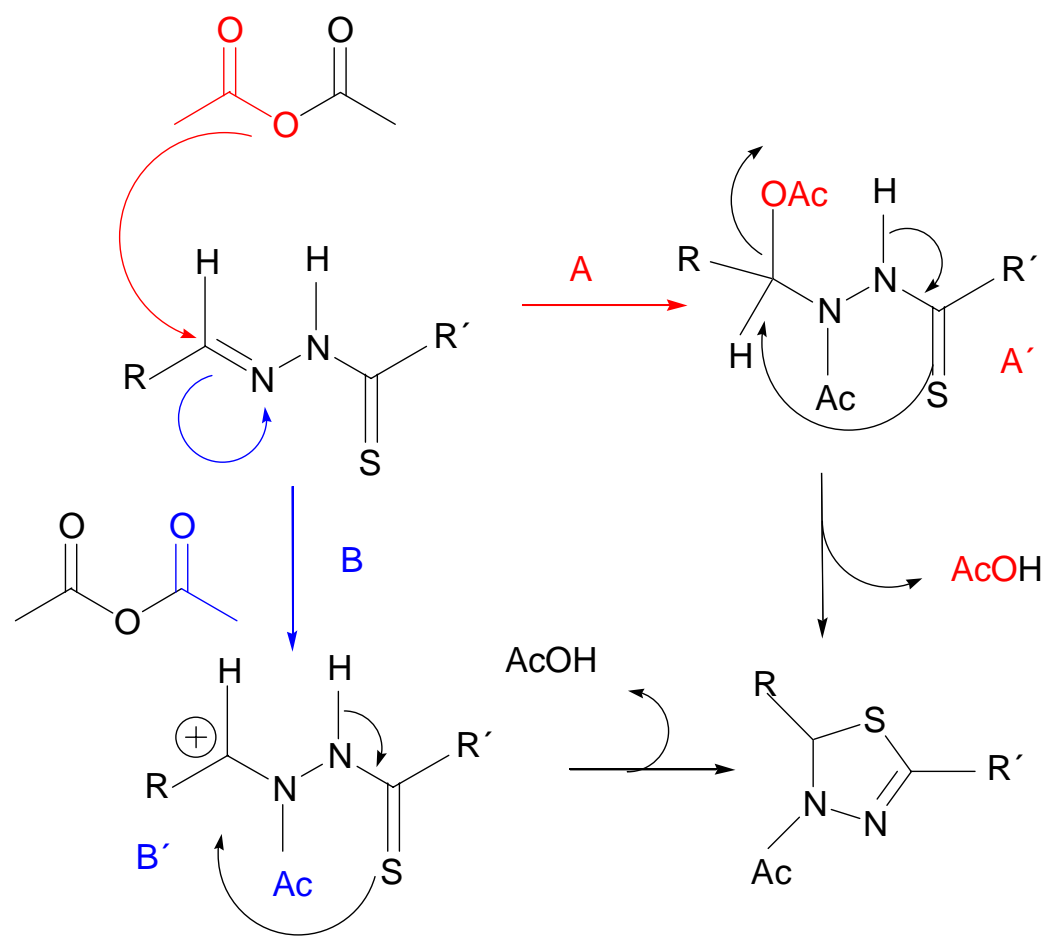

Scheme 2. Proposed mechanisms for the heterocyclization reaction. 
Both pathways (A and B) imply an intramolecular nucleophilic attack of the sulphur atom on the $C-\mathrm{N}-\mathrm{N}-\mathrm{CS}$ carbon atom in the intermediate $\left(\mathrm{A}^{\prime}\right.$ or $\left.\mathrm{B}^{\prime}\right)$. In the literature ${ }^{5}$ it is suggested that such an attack takes place from the more shielded face of the molecule, in such a way as to force the N-Ac group (bulkier than the sulphur atom) to occupy the less shielded face. This type of behavior has been clearly observed in the preparation of the TDZ derivative from some terpenones: mentone, fenchone and camphor. ${ }^{4}$

In the present work, these studies of heterocyclization were extended to other TSC derived from other natural terpenones. The aim was to evaluate the presence of an exo and endo conjugated double bond with the imino group, as well as terpenone topography in the stereoselection observed in the end product (TDZ).

\section{Results and Discussion}

Ketones used as starting material were pulegone 1, verbenone 2, verbanone 3 and thujone 4.

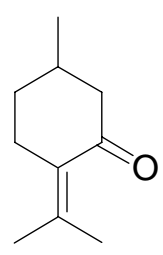

1

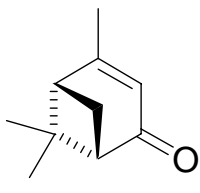

2

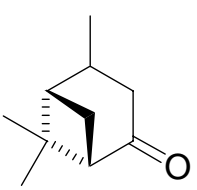

3

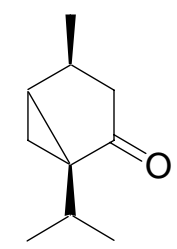

4

The preparation of the TSC derivative from pulegone $\mathbf{1}$ and verbenone $\mathbf{2}$ had been previously described $^{6}$ under the same conditions employed to obtain other TSC starting from saturated terpenones. When attempting the heterocyclization of these unsaturated TSC, it was observed that the reactions produced a considerable mixture of products. If one keeps in mind that one of the proposed alternative mechanisms (Scheme 2, pathway B) for the heterocyclization reaction involves the formation of a resonant carbocation species, which proved to be allyl in the particular case of the TSC from ketones 1 and 2 (Scheme 2, pathway B), most likely, this carbocation should be responsible for the complex mixture of reaction products through diverse conversions. Nevertheless, although with low yields it was possible to isolate and to characterize one TDZ for the TSC derivated from 1 and 2.

The heterocyclization of pulegone TSC (1) in the presence of acetic anhydride and pyridine led to a crude reaction mixture whose ${ }^{13} \mathrm{C}$ NMR showed the presence of a single spirane carbon atom at $\delta 82.2 \mathrm{ppm}$, although numerous $\mathrm{C}$ aliphatic atoms were observed, corresponding to a mixture of products. Exhaustive purification of such crude product allowed isolating a pure fraction corresponding to TDZ 5 (yield $55 \%$ ). The assignment of ${ }^{1} \mathrm{H}$ and ${ }^{13} \mathrm{C}$ NMR spectra to 5 (Figure 1) was carried out by 2D experiments (COSY, HMQC and NOESY) and by comparison with the assignment carried out previously for mentone, ${ }^{4}$ since NOESY experiments precluded unequivocal configuration assignment of the new chiral center. 

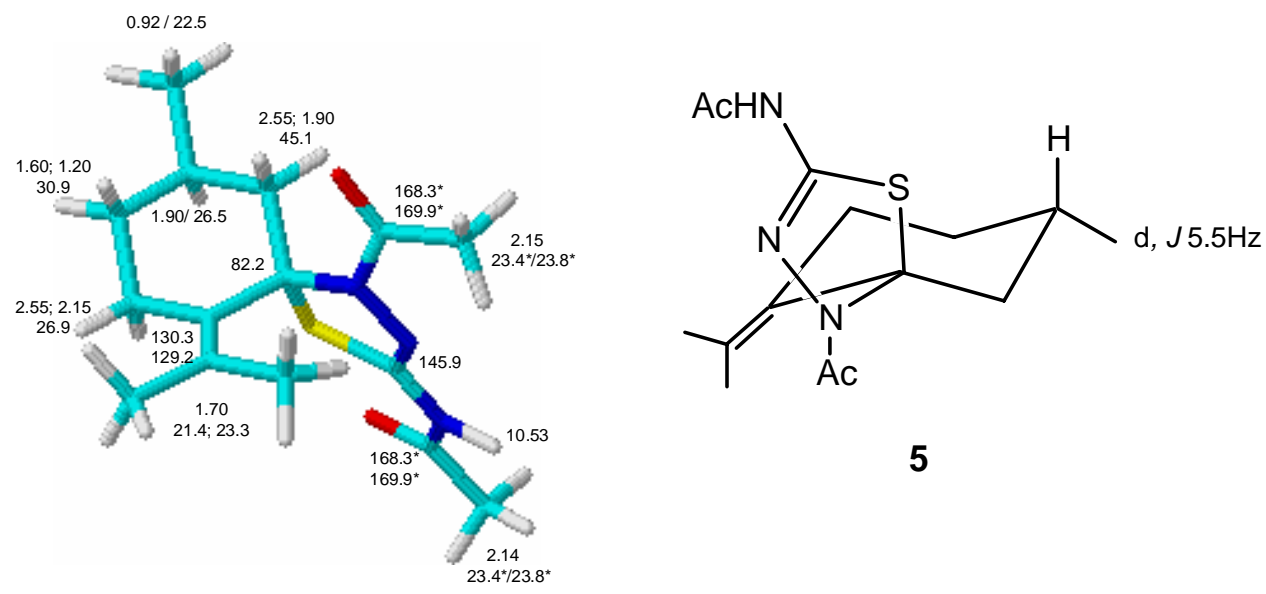

5

Figure 1. Assignment of NMR data $\left({ }^{1} \mathrm{H}\right.$ and $\left.{ }^{13} \mathrm{C}\right)$ of pulegone-TDZ 5.

In the case of the TSC derivative from verbenone 2, TDZ 6 was isolated, though with an even lower yield (32\%). NMR experiments (COSY, HMQC and NOESY) allowed assigning the different carbon and hydrogen atoms of 6 unequivocally (Figure 2). The configuration of the new chiral carbon was assigned tentatively, keeping in mind what had already been observed for the other terpenones, that is, the approach of the sulphur atom from the more hindered face in the molecule (gem-dimethyl bridge) that would lead to TDZ 6.
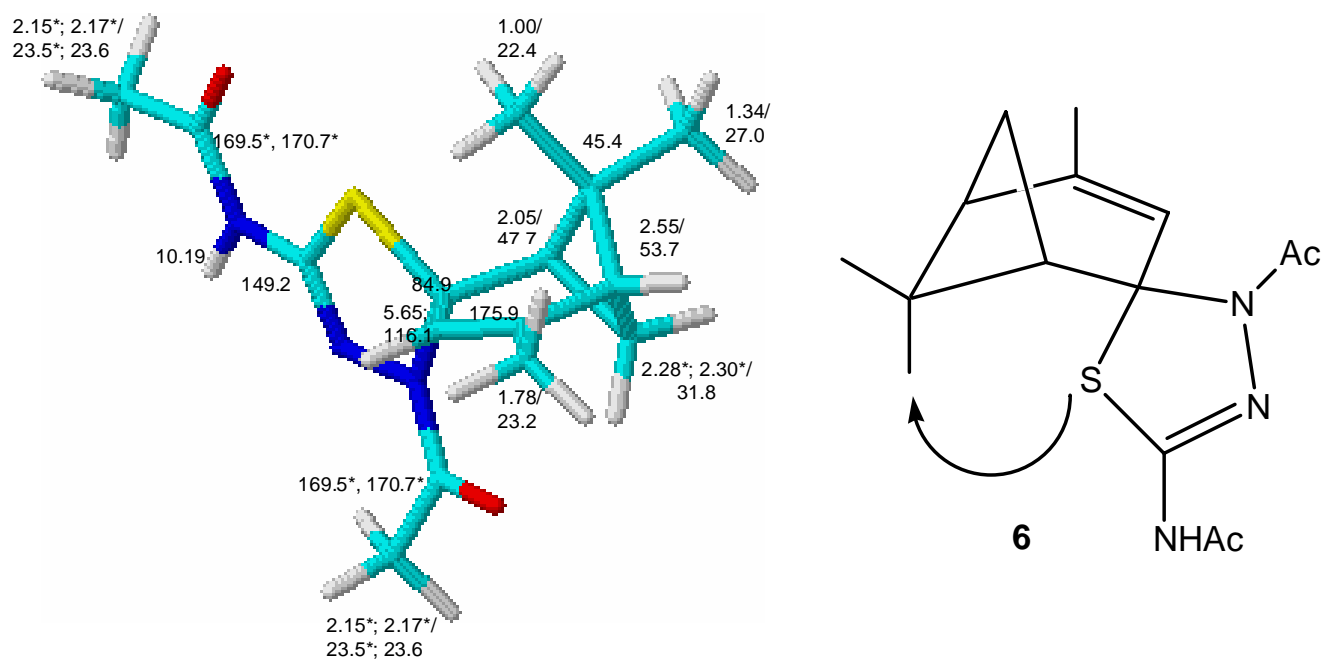

Figure 2. Assignment of NMR data $\left({ }^{1} \mathrm{H}\right.$ and $\left.{ }^{13} \mathrm{C}\right)$ of verbenone-TDZ 6.

In the case of verbenone, besides the effect of the double bond, the existence of the bicyclic bridge with the gem-dimethyl grouping would be expected to influence the course of the reaction, so that it was decided to evaluate the behavior of the dihydro derivative. Accordingly, 
verbenone (2) was reduced catalytically to verbanone (3) ${ }^{7}$ and TSC 7 prepared and treated with acetic anhydride and pyridine ${ }^{4}$ to render the corresponding TDZ 8 with very good yield (85\%) and diastereoselectivity.

This result would indicate the negative influence of the double bond, more than the steric hindrance of the bicyclic system, in the formation of the heterocycle. In order to assign the configuration of the new chiral center formed in $\mathbf{8}$, an exhaustive NMR study was carried out, C$\mathrm{H}$ correlation allowed the unequivocal assignment of each $\mathrm{C}$ and $\mathrm{H}$ atom. In turn, NOESY allowed, tentatively, assignment of the configuration of the new chiral center (Figure 3).
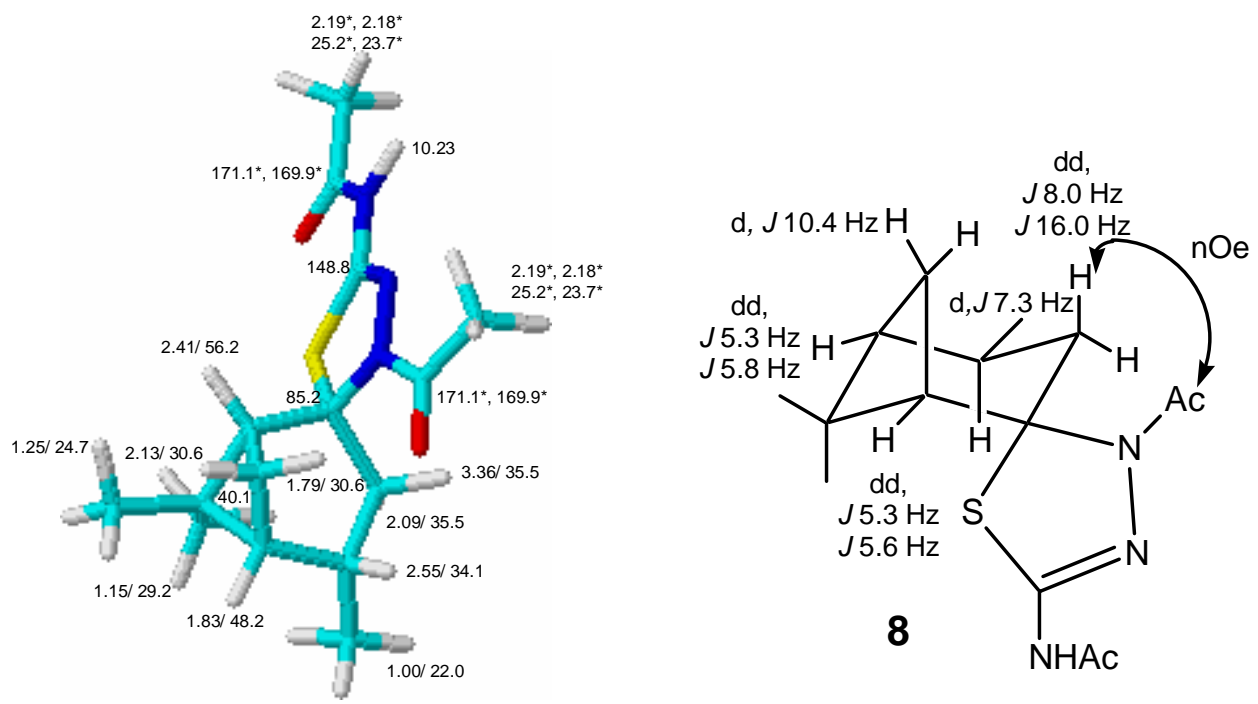

Figure 3. Assignment of NMR data $\left({ }^{1} \mathrm{H}\right.$ and $\left.{ }^{13} \mathrm{C}-\mathrm{NMR}\right)$ of verbanone-TDZ 8.

The marked deshielding observed in the hydrogen atom ( $\delta 3.36 \mathrm{ppm})$, in axial position of the six-membered ring, is attributable to the anisotropic effect exerted by the carbonyl group of the acetyl moiety linked to the $\mathrm{N}-3$ atom of the heterocyclic system, which would validate the configuration shown in Figure 3 for the spirane center. This finding reinforces the hypothesis that cyclization occurs from the more hindered face of the molecule (gem-dimethyl bridge). Compound 8 was crystallized and the crystals obtained were amenable to crystallographic determination (Figure 4), thus corroborating unequivocally the assignment made by the NMR experiments.

The behavior of the TSC derived from (-)-thujone 9, TSC already described in the literature, was also studied in order to evaluate the steric hindrance of the cyclopropyl group in the cyclization. On the other hand, this study is also interesting because cyclopropanes behave in some respects like double-bond compounds. ${ }^{8}$

Cyclization was carried out under the habitual conditions and produced two diastereoisomers, $\mathbf{1 0}$ and $\mathbf{1 1}$ (tentatively assigned) (Figure 5), in a 3:1 ratio, with a chemical yield lower than the one observed in the case of verbanone-TDZ 8. NOESY experiments confirmed that the 
diastereoisomers are due to the formation of two distinct configurations in the new chiral center (spirane carbon) and not to the isomerization of the thujone skeleton, although they precluded the unequivocal assignment of the configuration in the new center in each diastereoisomer.

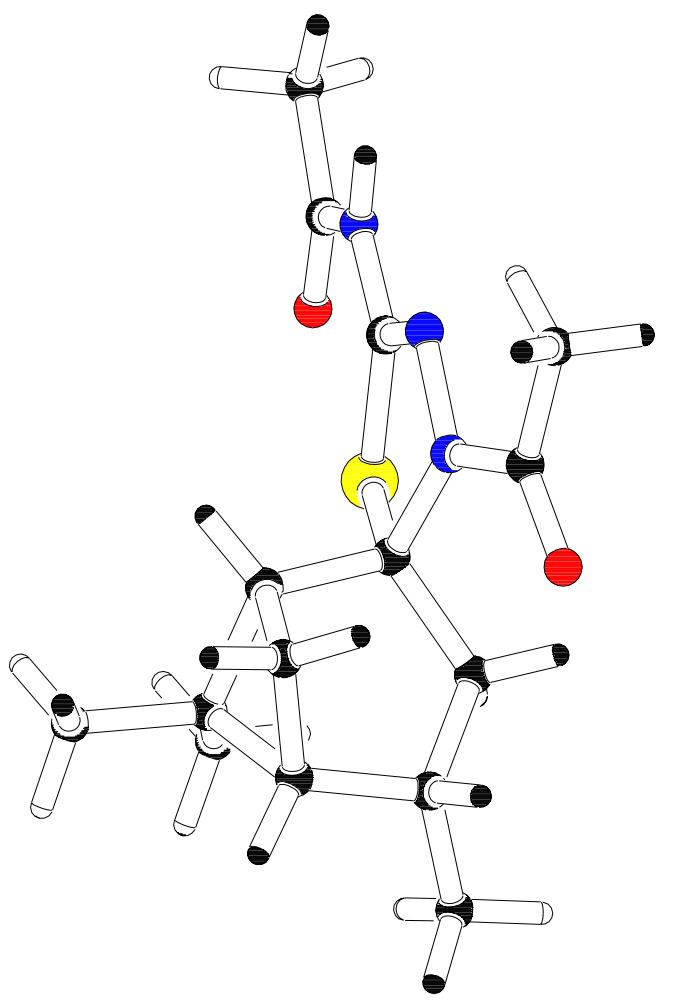

Figure 4. Molecular structure of verbanone-TDZ 8.

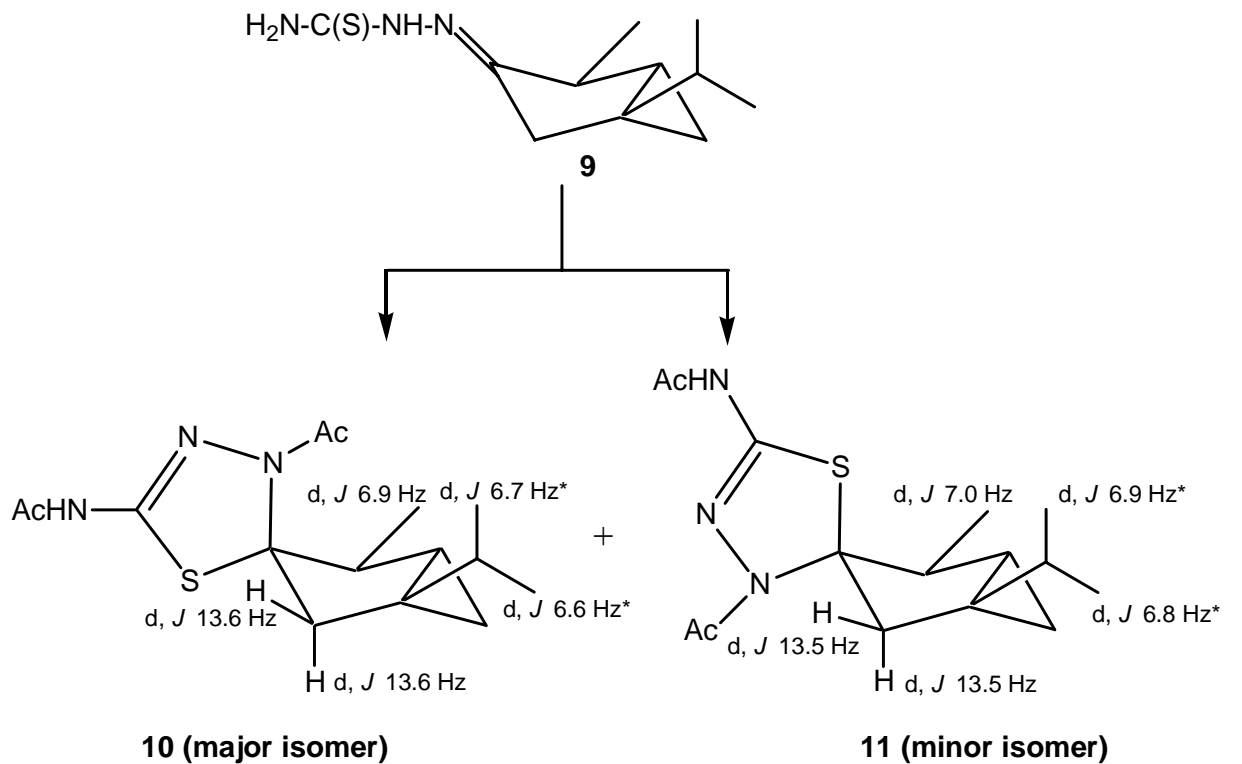




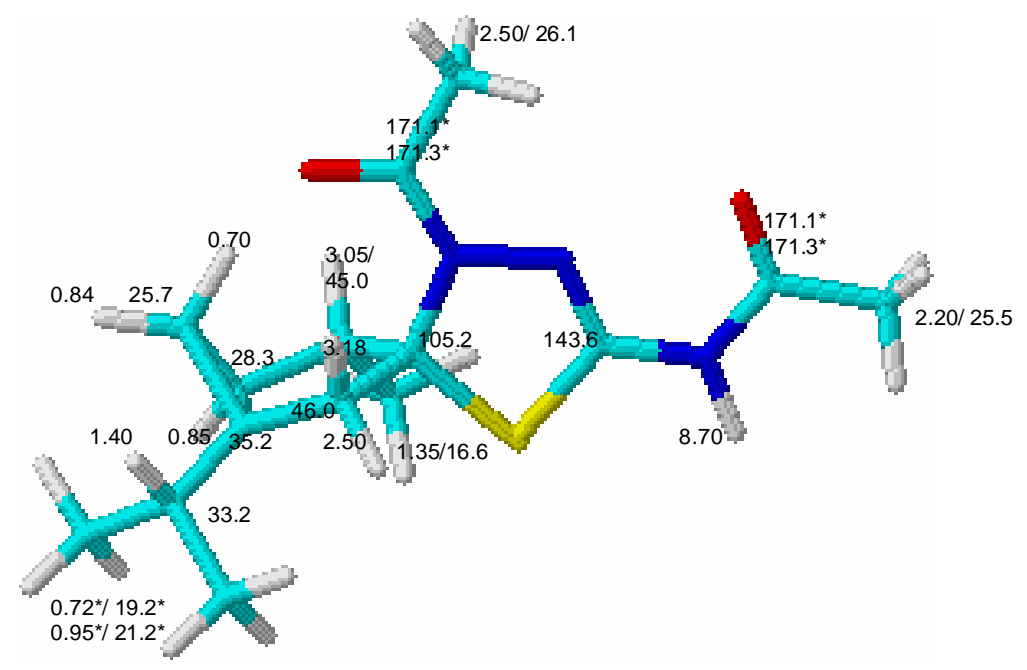

10 major isomer

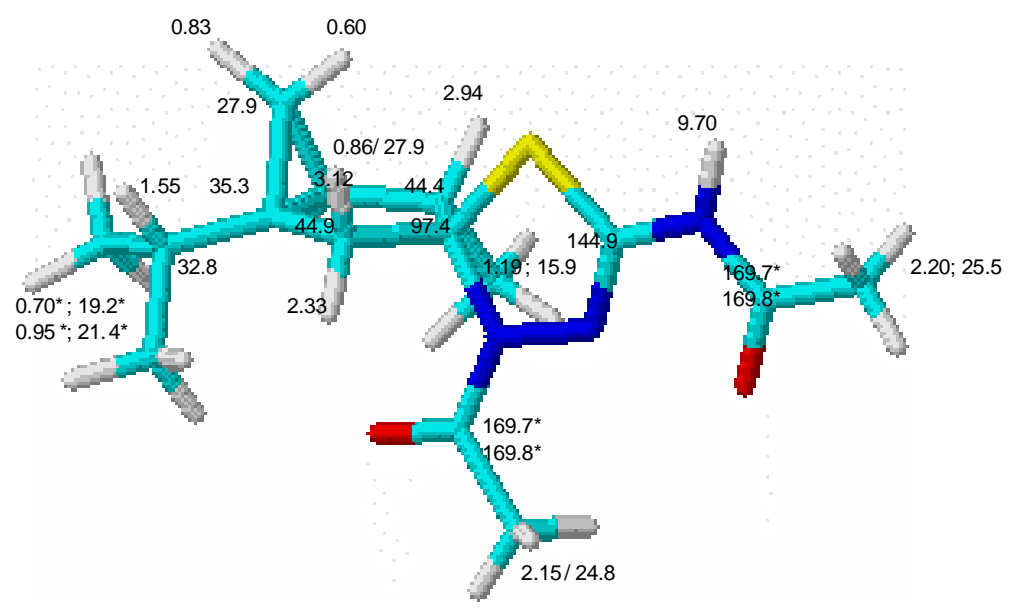

11 minor isomer

Figure 5. Assignement of NMR data $\left({ }^{1} \mathrm{H}\right.$ and $\left.{ }^{13} \mathrm{C}-\mathrm{NMR}\right)$ of thujone-TDZ isomers $\mathbf{1 0}$ and $\mathbf{1 1}$.

Perhaps the lack of a more clearly hindered face in the case of TSC 9 is responsible for the production of the two diastereoisomers.

Finally, and as pointed out in the introduction, we have already described, from camphor 12, through TSC 13, the preparation of the TDZ $\mathbf{1 4}^{4}$ (Scheme 3) and tentatively assigned the configuration of the new chiral center of $\mathbf{1 4}$ by NMR experiments. ${ }^{4}$ 


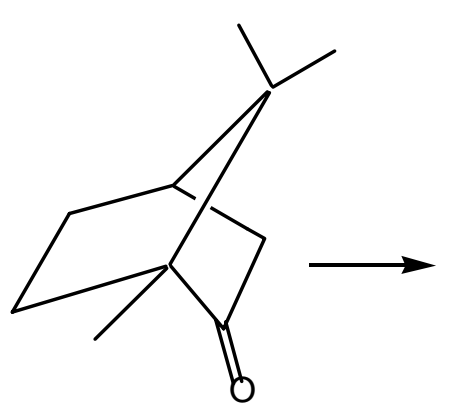

12

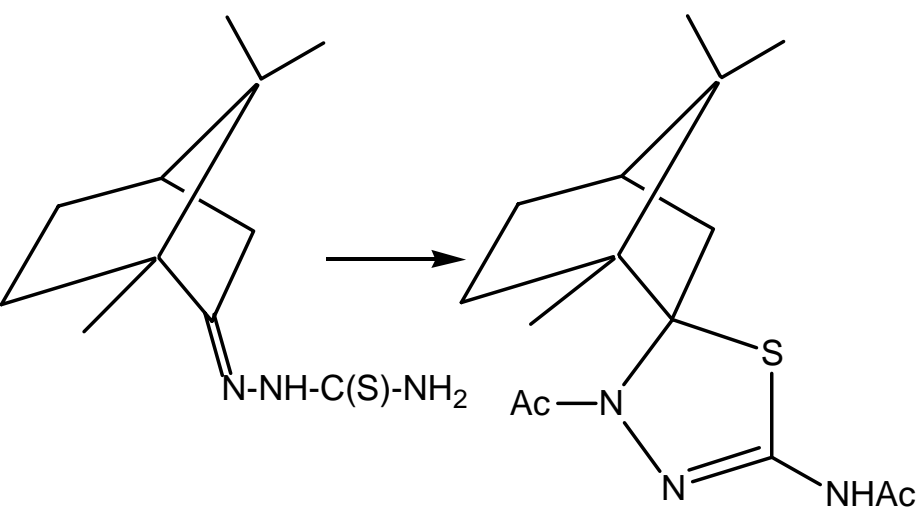

13

14

Scheme 3. Synthesis of camphor-TDZ 14 from camphor 12.

Now, the unequivocal assignment of its configuration has been carried out by single crystal X-ray structural determination (Figure 6).

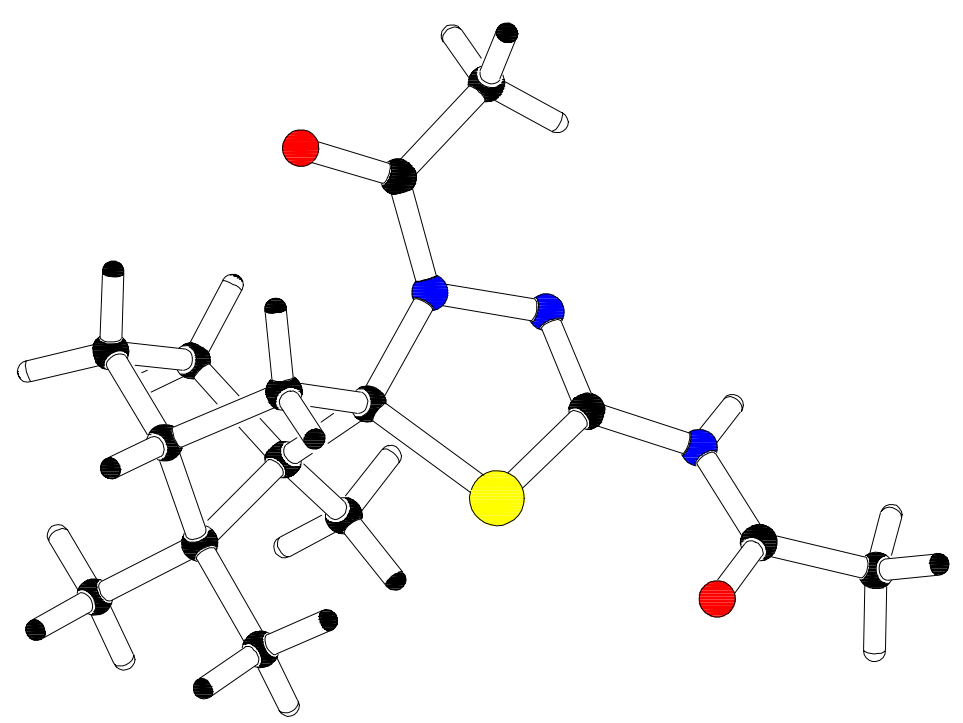

Figure 6. Molecular structure of camphor-TDZ 14 in solid state.

Different crystallization experiments, achieved in order to obtain suitable single crystals, have provided two crystal structures of the compound 14. In both polymorphs the molecule shows the same conformation. Moreover, the same hydrogen bonding pattern can be observed in the two crystal phases of $\mathbf{1 4}$ yielding infinite chains where each molecule is bonded to two neighbours through CONH...OC hydrogen bonds (Figure 7, Table 1). All chains are parallel and the two polymorphs arise from two different packings of these chains. 


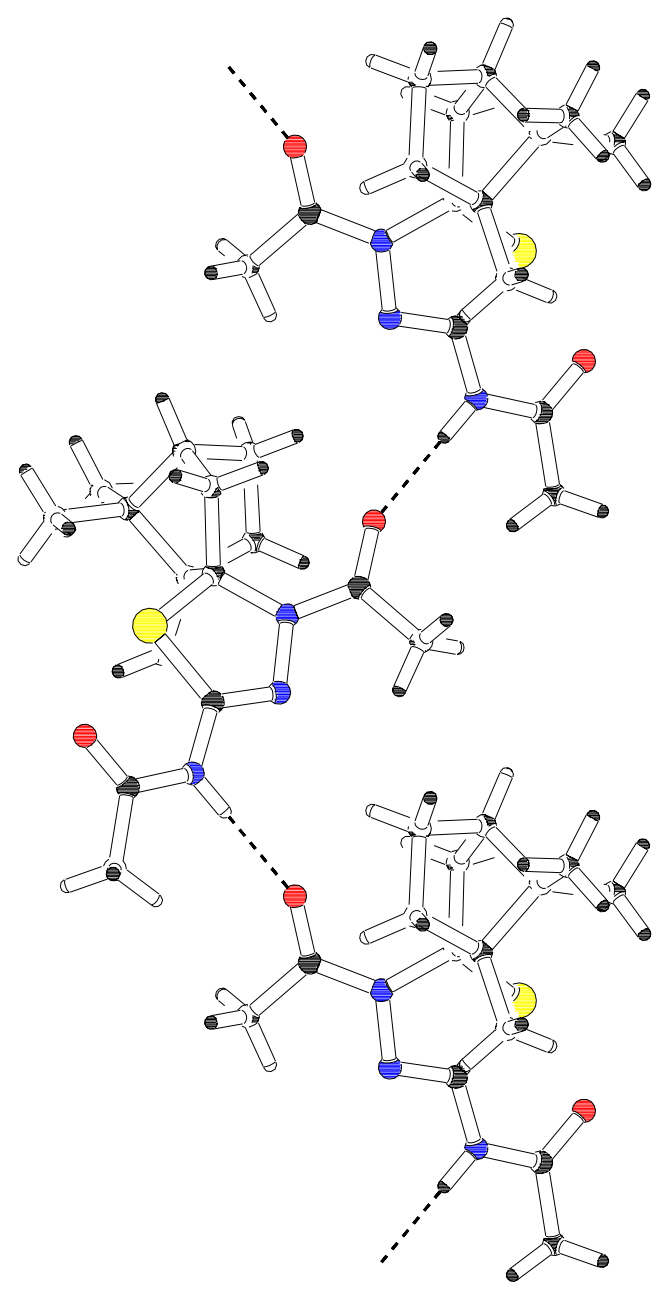

Figure 7. Intermolecular hydrogen bonds forming infinite chains in crystal structures of 14.

Table 1. Geometry of intermolecular hydrogen bonds forming infinite chains in polymorphs of 14

\begin{tabular}{ccccc}
\hline Polymorph & $\mathrm{N}-\mathrm{H}(\AA)$ & $\mathrm{N} . . . \mathrm{O}^{(\mathrm{s})}(\AA)$ & $\mathrm{H} \ldots \mathrm{O}^{(\mathrm{s})}(\AA)$ & $\mathrm{N}-\mathrm{H} \ldots \mathrm{O}^{(\mathrm{s})}\left({ }^{\mathrm{o}}\right)$ \\
\hline 14-PI & $0.88(3)$ & $2.818(4)$ & $1.94(3)$ & $174(3)$ \\
14-PII & $0.82(4)$ & $2.827(4)$ & $2.02(4)$ & $168(4)$ \\
\hline
\end{tabular}

(s) Neighbour molecule: $(-\mathrm{x}+1, \mathrm{y}-1 / 2,-\mathrm{z}+1 / 2)$ for 14-PI; $(-\mathrm{x}+1 / 2, \mathrm{y}-1 / 2,-\mathrm{z}+1)$ for 14-PII. 


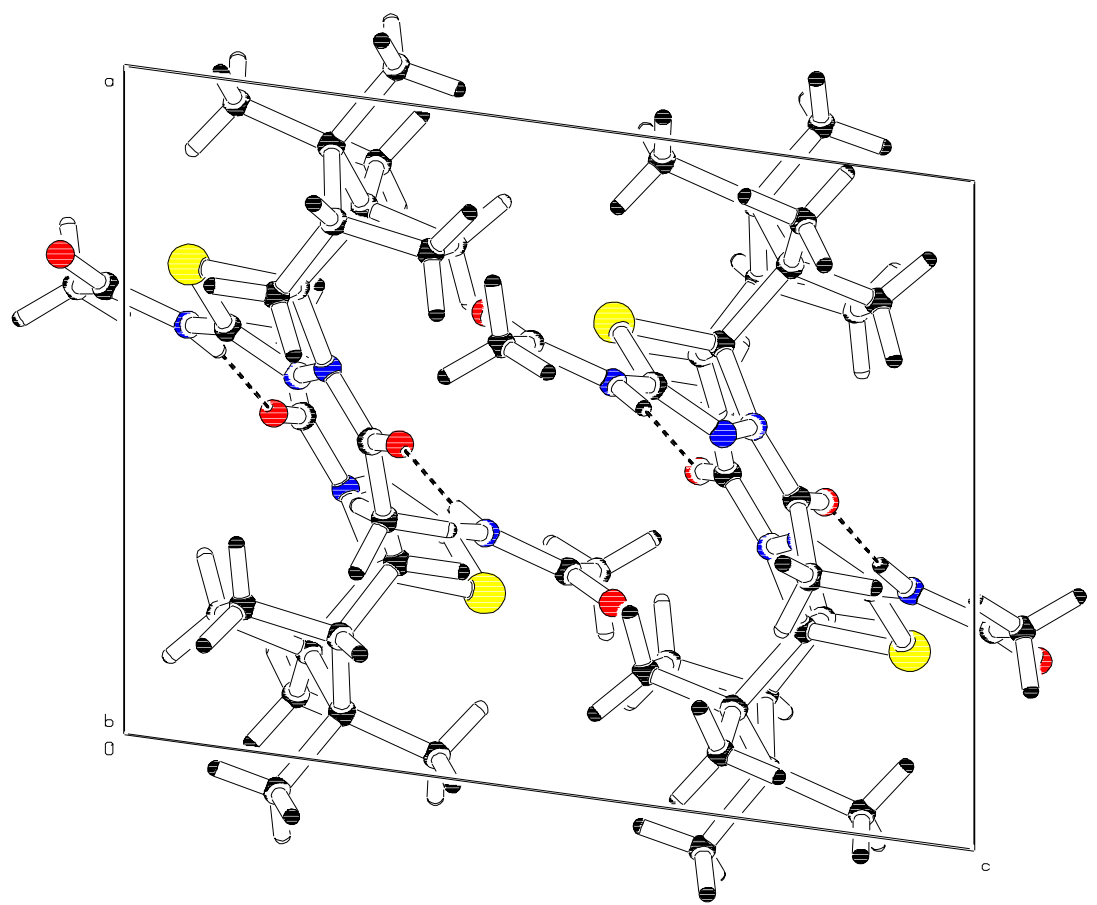

14-PI

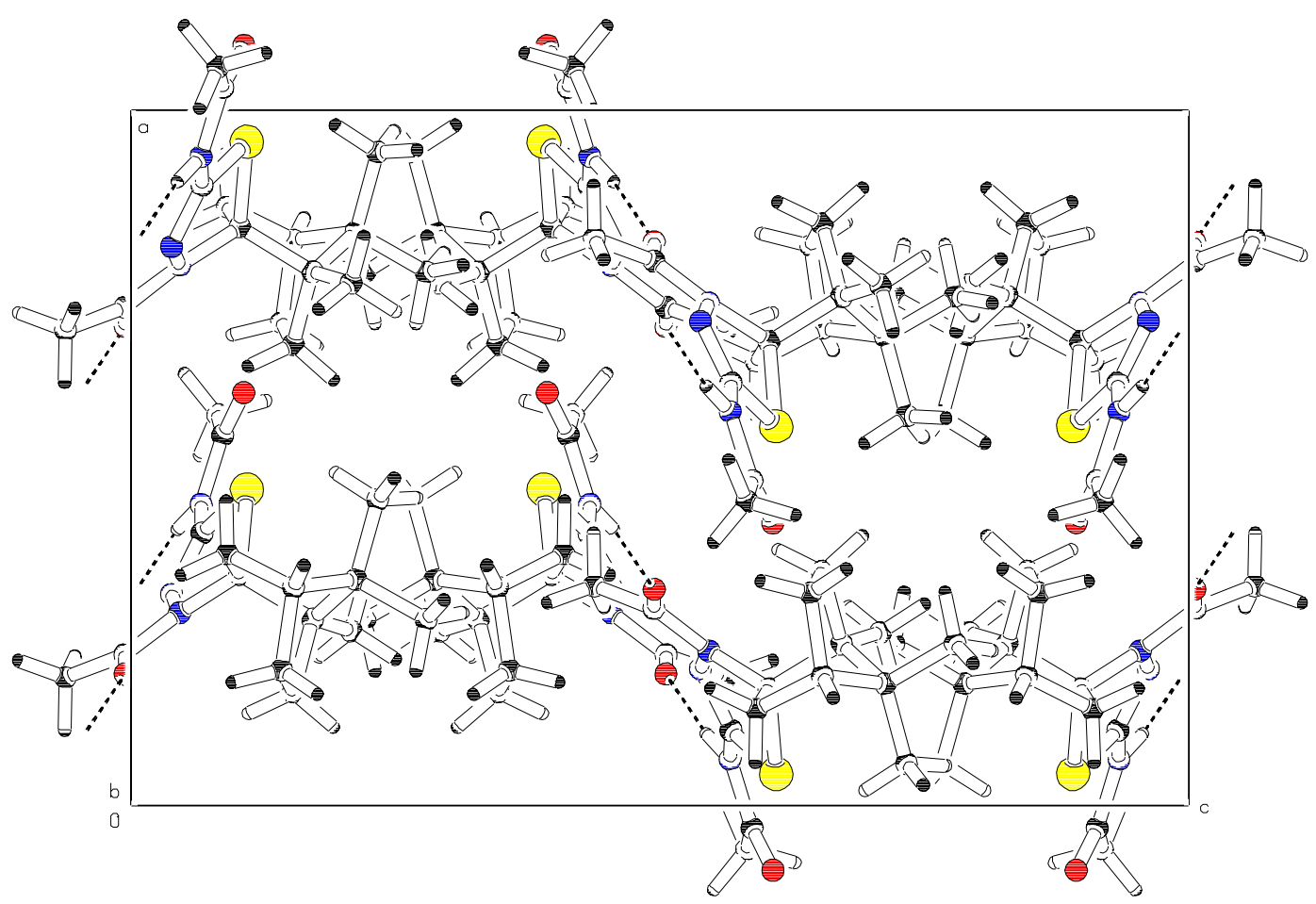

14-PII

Figure 8. Crystal structures of polymorphs of 14 viewed along the hydrogen-bond chain direction., [010]. 


\section{Conclusions}

In the present work, we were able to check the negative influence of the double $\mathrm{C}=\mathrm{C}$ bond conjugated to the $\mathrm{C}=\mathrm{N}$ group in the cyclization reaction of TSC, derived from terpenones $\mathbf{1}$ and 2.

We also found new examples, in addition to those previously described, ${ }^{4}$ where we verified the influence of the steric hindrance present in TSC concerning the favored face for TDZ ring closure. In such a sense, we contribute with crystallographic data of two TDZ, 8 and 14, clearly depicting such a situation and reinforcing, even further, our hypothesis regarding the influence of steric hindrance on the diastereoselection found, since again the previous configuration assignment by NMR is corroborated in that the sulphur atom leads to ring closure by attacking from the more hindered face of the molecule.

In cases where the starting chiral TSC fails to show a clearly favored attack face, as in TSC thujone $\mathbf{9}$ cyclization, a mixture of TDZ, 10 and 11, diastereoisomers is obtained.

\section{Experimental Section}

General Procedures. Melting points were measured on an Unimelt or and on an Electrothermal IA 9000 apparatus and are uncorrected. IR spectra were recorded as a film with a Spectrum one FT-IR spectrometer Perkin Elmer. ${ }^{1} \mathrm{H}$ and ${ }^{13} \mathrm{C}$ NMR spectra and heteronuclear correlation spectroscopy and NOE experiments were recorded on a Bruker $400-\mathrm{MHz}$, or in a Bruker 300$\mathrm{MHz}$ spectrometer in $\mathrm{CDCl}_{3}$ solutions. Chemical shifts are expressed in ppm (relative to the solvent). High resolution mass spectra (HRMS) were determined in a VG AutoSPec (Micromass Inst.). Thin layer chromatography (tlc) and preparative thin layer chromatography (p-tlc) were performed on Silica Gel $\mathrm{GF}_{254}$ (Merck); the optical rotations were determined, in solution of chloroform at $20^{\circ} \mathrm{C}$ and $589 \mathrm{~nm}$, with a Perkin Elmer 141 polarimeter.

Verbanone thiosemicarbazone (7). Title compound was prepared from the equimolecular quantity of (-)-verbanone ${ }^{7}$ and thiosemicarbazide dissolved in ethanol. The mixture was heated at reflux (nearly $36 \mathrm{~h}$ ) monitoring the reaction by tlc. Evaporation of the solvent under reduced pressure gave the corresponding thiosemicarbazone. It was purificated by $\mathrm{p}$-tlc (eluent solvent: chloroform) giving a crystalline solid (yield $97 \%$ ); m.p:119-121 ${ }^{\circ} \mathrm{C}$; IR $v_{\max }\left(\mathrm{cm}^{-1}\right) 3428,3253$, $3150\left(\mathrm{NH}\right.$ and $\left.\mathrm{NH}_{2}\right), 1588(\mathrm{C}=\mathrm{N}), 1498(\mathrm{C}=\mathrm{S})$ and $1286(\mathrm{C}=\mathrm{S}) .{ }^{1} \mathrm{H}-\mathrm{NMR} \delta 0.89(\mathrm{~s}, 3 \mathrm{H}), 1.15(\mathrm{~d}$, $J=7.3 \mathrm{~Hz}, 3 \mathrm{H}), 1.30$ (s, 3H), 1.17 (m, 1H), 2.01 (td, $J=5.6,1.9 \mathrm{~Hz}, 1 \mathrm{H}), 2.15$ (dd, $J=19.0,5.0$ Hz, 1H), 2.33 (m, 1H), 2.56 (m, 2H), 2.84 (dd, $J=19.1,10.5 \mathrm{~Hz}, 1 \mathrm{H}), 6.59$ (bs, 1H), 7.23 (bs, $1 \mathrm{H})$ and $8.64(\mathrm{bs}, 1 \mathrm{H}) \mathrm{ppm} .{ }^{13} \mathrm{C}-\mathrm{NMR} \delta 21.9,24.9,27.2\left(\mathrm{CH}_{3}\right), 29.8,30.9,32.3,40.9,47.7,51.6$, 60.7, 179.0 ppm. $[\alpha]_{D}+41.5^{\circ}(c=1)$. Anal. calcd for $\mathrm{C}_{11} \mathrm{H}_{19} \mathrm{~N}_{3} \mathrm{~S}$ : C, 58.63; H, 8.50; N, 18.65; S, 14.23. Found: C, 58.60; H, 8.60; N, 18.60; S, 14.29. 


\section{Synthesis of thiadiazolines. General procedure}

Thiosemicarbazone $(0.25 \mathrm{mmol})$ was dissolved in pyridine:acetic anhydride $1: 1(0.5 \mathrm{~mL})$ and the mixture was heated at $110{ }^{\circ} \mathrm{C}$ during $1.30 \mathrm{~h}$ with magnetic stirring. The crude product was purified by p-tlc eluting with hexane:ethylacetate:chloroform 3.5:2.0:1.5 or by recrystallization as is indicated in each case.

Pulegone thiadiazoline (5). Compound 5 was obtained from pulegone thiosemicarbazone 1. This compound was purified by p-tlc and was isolated as an oil (yield $58 \%$ ); $v_{\max }(\mathrm{film}) / \mathrm{cm}^{-1}$ 3424 weak $(\mathrm{NH}), 1694-1612$ broad band $(\mathrm{C}=\mathrm{O}),(\mathrm{C}=\mathrm{N}) .{ }^{1} \mathrm{H}-$ and ${ }^{13} \mathrm{C}-\mathrm{NMR}$ : see Figure 1. [ $\left.\alpha\right]_{\mathrm{D}}$ $9.8^{\circ}(c=1)$. HR CIMS calc for $\mathrm{C}_{15} \mathrm{H}_{23} \mathrm{~N}_{3} \mathrm{O}_{2} \mathrm{~S}: 309.1511$. Found: 309.1511 .

Verbenone thiadiazoline (6). Compound 6 was obtained from verbenone thiosemicarbazone 2. This compound was purified by p-tlc and isolated as a syrup (yield 32\%); $v_{\max }\left(\mathrm{cm}^{-1}\right)$ 3429-3310 broad band $(\mathrm{NH}), 1645,1609(\mathrm{C}=\mathrm{O}),(\mathrm{C}=\mathrm{N}) .{ }^{1} \mathrm{H}$ - and ${ }^{13} \mathrm{C}-\mathrm{NMR}$ : see Figure 2. $[\alpha]_{\mathrm{D}}-104.5^{\circ}$ $(c=1)$. Anal. calc for $\mathrm{C}_{15} \mathrm{H}_{21} \mathrm{~N}_{3} \mathrm{O}_{2} \mathrm{~S}: \mathrm{C}, 58.62 ; \mathrm{H}, 6.89 ; \mathrm{N}, 13.67 ; \mathrm{S}, 10.43$. Found: C, 58.57; H, $6.85 ; \mathrm{N}, 13.61 ; \mathrm{S}, 10.53$.

Verbanone thiadiazoline (8). Compound 8 was obtained from verbanone thiosemicarbazone 7 (yield $85 \%$ ); m.p. 188-189 ${ }^{\circ} \mathrm{C}$ (from ethyl acetate). $v_{\max }\left(\mathrm{cm}^{-1}\right) 3221,3165,3078(\mathrm{NH}), 1662$ $(\mathrm{C}=\mathrm{N}), 1611,1383(\mathrm{~N}-\mathrm{CO}) ;{ }^{1} \mathrm{H}$ - and ${ }^{13} \mathrm{C}-\mathrm{NMR}$ : see Figure $3 ;[\alpha]_{\mathrm{D}}-18.5^{\circ}(c=0.442)$. HR CIMS calc for $\mathrm{C}_{15} \mathrm{H}_{23} \mathrm{~N}_{3} \mathrm{O}_{2} \mathrm{~S}: 309.1511$. Found 309.151602.

Thujone thiadiazoline (10, 11). Compound 10 and 11 were obtained from thujone thiosemicarbazone 9, and were purified by p-tlc. Compound 10 (yield $60 \%$ ) was obtained as a syrup $[\alpha]_{\mathrm{D}}-24.9^{\circ}(c=1)$; IR $v_{\max }\left(\mathrm{cm}^{-1}\right) 3436(\mathrm{NH}), 1664(\mathrm{C}=\mathrm{O}$ amide $), 1619(\mathrm{C}=\mathrm{O}$ amide), $1500(\mathrm{C}=\mathrm{N}) .{ }^{1} \mathrm{H}-$ and ${ }^{13} \mathrm{C}-\mathrm{NMR}$ : see Figure 5. Compound $\mathbf{1 1}$ (yield 18\%) was obtained as a syrup, $[\alpha]_{D^{-}} 36.6^{\circ}(c=1)$; IR $v_{\max }\left(\mathrm{cm}^{-1}\right) 3436(\mathrm{NH}), 1655(\mathrm{C}=\mathrm{O}$ amide $), 1619(\mathrm{C}=\mathrm{O}$ amide $), 1499$ $(\mathrm{C}=\mathrm{N})$. ${ }^{1} \mathrm{H}$ - and ${ }^{13} \mathrm{C}-\mathrm{NMR}$ : see Figure 5. Anal. calc for $\mathrm{C}_{15} \mathrm{H}_{23} \mathrm{~N}_{3} \mathrm{O}_{2} \mathrm{~S}$ : C, 58.23; H, 7.49; N, 13.58; S, 10.36. Found: C, 58.19; H, 7.45; N, 13.52; S, 10.39 .

\section{X-Ray diffraction analysis}

General data. Data were collected at 293(2) K on an Enraf Nonius CAD4 diffractometer using MoK $\alpha$ radiation $\left(\lambda=0.71069 \AA\right.$ ). Structures were solved by direct methods (SHELXS-86) ${ }^{10}$ and refined by least-squares on $\mathrm{F}^{2}$ for all reflections (SHELXL-97). ${ }^{11}$ Non-hydrogen atoms were refined anisotropically. The hydrogen atom bonded to nitrogen was located on a difference Fourier map and refined isotropically. Hydrogen atoms bonded to carbon were placed in calculated positions with isotropic displacement parameters 1.5 (methyl $\mathrm{H}$ ) or 1.2 (the rest) times the $\mathrm{U}_{\mathrm{eq}}$ values of corresponding carbons. Crystal structures have been deposited at the Cambridge Crystallographic Data Centre and allocated the deposition numbers CCDC 272871 (8), CCDC 272872 (14-PI), and CCDC 272873 (14-PII). 


\section{Crystal and refinement data for compound 8}

Suitable crystals were obtained by crystallization from 2-butanone. Crystal dimensions: $0.32 \mathrm{x}$ 0.29 x $0.07 \mathrm{~mm}$. Empirical formula $\mathrm{C}_{15} \mathrm{H}_{23} \mathrm{~N}_{3} \mathrm{O}_{2} \mathrm{~S}$. Molecular weight 309.42. Crystal system: monoclinic. Space group: $\mathrm{P} 2{ }_{1} / \mathrm{c}\left(\mathrm{N}^{\circ} 14\right)$. Lattice parameters: $a=11.999(3) \AA, b=9.593(3) \AA, c=$ 14.751(8) $\AA, \beta=110.38(3)^{\circ}, V=1591.6(11) \AA^{3} . Z=4$. Calculated density: $1.291 \mathrm{~g} \mathrm{~cm}^{-3} . \mathrm{F}(000)$ $=664$. Independent reflections: 2799 . Refined parameters: 194 . Goodness-of-fit on $\mathrm{F}^{2}: 0.912$. $\mathrm{R}(\mathrm{F})=0.058$ for reflections with $\mathrm{I}>2 \sigma(\mathrm{I}), \mathrm{R}_{\mathrm{w}}\left(\mathrm{F}^{2}\right)=0.151$ for all data.

Crystal and refinement data for compound 14, polymorph I. Suitable crystals were obtained by crystallization from toluene. Crystal dimensions: $0.72 \times 0.43 \times 0.07 \mathrm{~mm}$. Empirical formula $\mathrm{C}_{15} \mathrm{H}_{23} \mathrm{~N}_{3} \mathrm{O}_{2} \mathrm{~S}$. Molecular weight 309.42. Crystal system: monoclinic. Space group: $\mathrm{P} 2{ }_{1} / \mathrm{c}\left(\mathrm{N}^{\circ} 14\right)$. Lattice parameters: $a=9.934(3) \AA, b=13.082(9) \AA, c=12.666(9) \AA, \beta=97.81(3)^{\circ}, \mathrm{V}=$ 1630.8(17) $\AA^{3} . Z=4$. Calculated density: $1.260 \mathrm{~g} \mathrm{~cm}^{-3} . \mathrm{F}(000)=664$. Independent reflections: 2868. Refined parameters: 194 . Goodness-of-fit on $\mathrm{F}^{2}: 0.939 . \mathrm{R}(\mathrm{F})=0.053$ for reflections with $\mathrm{I}>2 \sigma(\mathrm{I}), \mathrm{R}_{\mathrm{w}}\left(\mathrm{F}^{2}\right)=0.150$ for all data.

Crystal and refinement data for compound 14, polymorph II. Suitable crystals were obtained by crystallization from ethanol. Crystal dimensions: 0.43 x 0.40 x $0.07 \mathrm{~mm}$. Empirical formula $\mathrm{C}_{15} \mathrm{H}_{23} \mathrm{~N}_{3} \mathrm{O}_{2} \mathrm{~S}$. Molecular weight 309.42. Crystal system: orthorhombic. Space group: Pcab $\left(\mathrm{N}^{\mathrm{o}} 61\right)$. Lattice parameters: $a=12.694(5) \AA, b=13.219(4) \AA, c=19.292(6) \AA, \mathrm{V}=3237.2(19)$ $\AA^{3} . \mathrm{Z}=8$. Calculated density: $1.270 \mathrm{~g} \mathrm{~cm}^{-3} . \mathrm{F}(000)=1328$. Independent reflections: 2846. Refined parameters: 194. Goodness-of-fit on $\mathrm{F}^{2}: 0.933 . \mathrm{R}(\mathrm{F})=0.070$ for reflections with $\mathrm{I}>2 \sigma(\mathrm{I})$, $\mathrm{R}_{\mathrm{w}}\left(\mathrm{F}^{2}\right)=0.185$ for all data.

\section{Acknowledgments}

This research was financially supported by Universidad de Buenos Aires and Consejo Nacional de Investigaciones Cientificas y Tecnológicas (CONICET)-Argentina

\section{References}

1. (a) Ali, S.; Alam, M. Archives of Pharmaceutical Research 1994, 17, 131. (b) Brousse, B. N.; Masa, R.; Moglioni, A. G.; Martins Alho, M. A.; D’Accorso, N. B.; Gutkind, G.; Moltrasio, G. Y. J. Chil. Chem. Soc. 2004, 49, 89. (c) Teitz, Y.; Ronen, D.; Vansover, A.; Stematsky, T. Antiviral Research 1994, 24, 305.

2. Andreae, S.; Schmitz, E.; Seeboth, H. J. Prakt. Chemie 1986, 328, 205.

3. Martins Alho, M. A.; Moglioni, A. G.; Brousse, B. N.; Moltrasio, G. Y.; D'Accorso N. B. ARKIVOC 2000, (iv), 627.

4. Brousse, B. N.; Moglioni, A. G.; Martins Alho, M. A.; Álvarez-Larena, A.; Moltrasio, G. Y.; D'Accorso, N. B. ARKIVOC 2002, (x), 14. 
5. Shamsuzzaman, M. A.; Anwar, S. J. Chem. Res. 1998, 824.

6. García, C. C.; Brousse, B. N.; Carlucci, M. J.; Moglioni, A. G.; Martins Alho, M. A .; Moltrasio, G. Y.; D’Accorso, N. B.; Damonte, E. B. Antiviral Chemistry \&Chemotherapy 2003, 14, 99.

7. Dr Ferretti O. and col. of the Universidad Nacional de La Plata-Argentina, kindly provided a sample of verbanone.

8. Noller, C. R. Química Orgánica; Tercera Edición: Editorial Interamericana S.A., 1968; p522.

9. Catalán, C. A. N. Arch. Bioquímica, Química y Farmacia, Tucumán 1977-1978, 20, 25.

10. Sheldrick, G. M. SHELXS-86. Crystallographic Computing 3. Sheldrick, G. M.; Krüger, C.; Goddard, R. Oxford University Press: Oxford, 1985.

11. Sheldrick, G. M. SHELXL-97. Program for the Refinement of Crystal Structures, Göttingen, 1997. 